\title{
Deconstrucción y Reconstrucción de la Identidad Cultural Europea. Ilustración, Romanticismo y Posmodernismo*
}

\author{
Pablo Sánchez Garrido** \\ Universidad CEU San Pablo, Madrid (España)
}

\begin{abstract}
The objective of this article is to describe the concept of European cultural identity derived from the postmodern deconstructionist vision. The study tracks the origins of this line of thinking to the ideas of the Enlightenment and the romanticism, discussing its anti-metaphysical component which makes it refuse any substantial idea of a European cultural identity. Additionally, it offers an analysis of the "ideology of the difference" that supports this theoretical-cultural statement, with its transfer to the dominant cultural-political discourse in the current integration process within the "New Europe". Contradicting this line of argumentation, the classical (Greco-Roman) and Christian origins are suggested as historical-axiological roots of an authentic European identity and as the foundation to overcome the spiritual and cultural decay suffered now by the "Old Europe".
\end{abstract}

Key Words.

European cultural identity, postmodernity, enlightenment, Romanticism, deconstruction, difference, christianity.

\section{Resumen}

El objetivo de este artículo es mostrar la concepción de la identidad cultural europea que se deriva de la visión deconstruccionista postmoderna. En el artículo se rastrean los orígenes ilustrados y románticos de esta corriente de pensamiento, así como su actual componente anti-metafísico, que lo hace contrario a toda idea sustantiva de una identidad cultural europea. La "ideología de la diferencia", que subyace a este planteamiento teórico-cultural, se analiza igualmente en su trasvase al discurso político-cultural dominante dentro del actual proceso de integración de la "Nueva Europa". Por el contrario, se apunta a los orígenes clásicos (grecorromanos) y cristianos como raíces histórico-

Fecha de recepción del artículo: 3 de mayo de 2007

Fecha de aprobación del artículo: 29 de junio de 2007

* El presente es resultado del proyecto de la investigación La identidad cultural de la nueva Europa ante el proceso de integración y globalización. Entre un pasado humanista y un futuro solidario. Investigación aprobada por el Ministerio de Educación y Ciencia (España), con referencia: SEJ200406207/CPOL, del cual es investigador principal Dalmacio Negro Pavón. La segunda parte de este texto, de próxima publicación, se titula: "La identidad cultural de Europa ante la postmodernidad. De la deconstrucción de J. Derrida a la reconstrucción de J. Habermas".

** Licenciado en Filosofía (Universidad de Navarra, España). Doctor por la Facultad de Ciencias Políticas y Sociología (Universidad Complutense de Madrid). Actualmente es Profesor y Coordinador del Área de Doctrina Social de la Iglesia, Universidad CEU San Pablo de Madrid. También ha impartido otras materias como Ética o Historia del Pensamiento Político. 
axiológicas de la auténtica identidad europea y como base desde la que superar la decadencia espiritual y cultural que sufre hoy la "Vieja Europa".

\section{Palabras clave.}

Identidad cultural europea, postmodernidad, Ilustración, Romanticismo, deconstrucción, diferencia, cristianismo.

\section{Problema y metodología del proyecto de investigación}

El artículo forma parte del proyecto de investigación titulado: "La identidad cultural de Europa ante el proceso de integración y globalización", aprobado por el Ministerio de Educación y Ciencia (España). El objetivo del proyecto es analizar la identidad cultural europea desde su tradición humanística e historia cultural, así como contrastar esta con las diversas concepciones que parten de la Modernidad. La metodología de este proyecto es interdisciplinar y humanística, integrando, por ello, a investigadores de diversas disciplinas, como Historia, Filosofía, Arte y Literatura.

\section{Introducción}

Una identidad colectiva es un gueto, un campo de concentración donde el individuo está secretamente clonado, para mantener la ficción de una homogeneidad que nunca existe. En las sociedades más primitivas esa condición ancilar del ser humano respecto de la colectividad es inevitable, pues de ella depende su supervivencia ante los fragores y peligros que lo rodean: la fiera, el rayo, las tribus enemigas. Pero a medida que progresa el conocimiento, el dominio de la naturaleza, el desarrollo de la vida social, un principio de diferenciación se va abriendo paso en esos rebaños humanos y el individuo va apareciendo, ganando un espacio de iniciativas y derechos, que, al cabo de los siglos, harán de él un ser libre y soberano. Ese proceso, que es el de la libertad en la historia, es la mejor hazaña de la historia europea [a la que Croce, con buena intuición, bautizó ‘una hazaña de la libertad'] y lo que constituye el mejor fundamento para la construcción de esa Europa en ciernes, una comunidad que debe concebirse como la realización de un futuro y no como la resurrección de un pasado.

En esa Europa ideal, democrática, liberal y libertaria, los ciudadanos podrán elegir su dios o no tener dioses, practicar una religión o ser ateos o agnósticos, y decidir la lengua en que quieran expresarse, el sexo que prefieran, el país, la ciudad o la aldea donde quieran vivir y trabajar, y no tendrán más limitaciones para ejercitar sus convicciones, costumbres y creencias que las que impidan coactar el derecho de los demás a ejercer esa misma libertad. Esa Europa no tendrá una identidad colectiva porque en ella habrá cuatrocientos millones de ciudadanos libres que representarán otras tantas identidades con matices y sesgos diferentes que, conviviendo dentro de unas leyes que consagren esa filosofía de respeto y tolerancia, irá empujando al planeta hacia el designio kantiano de la paz universal. (Vargas Llosa, 2004).

No quisiera proseguir sin advertir que las palabras anteriores no pertenecen al autor de este texto. En realidad, son palabras del escritor e intelectual, Mario Vargas Llosa. Pero se han traído a colación porque reflejan y sintetizan con claridad diáfana la actitud de rechazo hacia el concepto de identidad cultural aplicado a Europa 
que late en gran parte de la neo-ilustración romántica y posmoderna de nuestros días. Asimismo, reflejan con la misma claridad la "Europa" nueva que ciertos sectores ideológicos pretenden reconstruir una vez lograda la deconstrucción de la vieja Europa. Para lograr este objetivo, como se expondrá a continuación, se pretende hacer una tabla rasa de la herencia cultural de Europa. Una vez superada la pars destruens, se trataría de hacer una criba ideológica o una selección de aquellos elementos $\mathrm{y}$ valores que una vez reinterpretados, sean compatibles con la reconstrucción de ése nuevo modelo ideológico, o "ideología europeísta", como D. Negro (2004) la ha denominado ${ }^{1}$. En este contexto, la insistencia denodada en una Europa nueva, no responde sólo a un intento de distinguir el actual proceso de integración de Europa del llamado Viejo continente, esa nueva Europa ampara una "nueva" redefinición ideológica de Europa. Esconde un nuevo rapto de Europa. Es enormemente revelador de lo que anima ese proceso de reconstrucción otro fragmento del mismo artículo de Vargas Llosa (2004), quien al preguntarse por el contenido de la "identidad cultural" de Europa, responde:

Quienes sostienen que el cristianismo es el rasgo definitorio y sustancial del carácter europeo se ven en apuros para conciliar aquella tradición con el espíritu de las luces y las consecuencias de la Ilustración, hija del viejo continente y fuente nutricia del laicismo, los derechos humanos y la democracia, nacidos, en gran medida, contra la oposición pugnaz del tradicionalismo católico.

Otro ejemplo de esta misma tendencia ideológica nos llevará desde la pseudo intelectualidad mediática hasta el ámbito de la pseudo intelectualidad política. Hace algunos meses, el que fuera presidente de la Comisión Europea, Romano Prodi, encargó a un grupo de sabios que reflexionara acerca de Europa ante el actual proceso de integración. Una de las conclusiones de este comité de sabios fue la imposibilidad de definir la identidad europea. Pero lo interesante no está en dicha afirmación, de por sí tan vaga que podría ser significar un reconocimiento de la complejidad de la Historia y cultura europeas. Lo peculiar está en los argumentos de esta conclusión. Éstos "sabios" justifican su conclusión señalando que "la cultura europea -en realidad, la propia Europa- no es un hecho. Es una tarea y un proceso. La identidad es algo que debe ser negociado por sus pueblos e instituciones", en otro lugar afirmaban "No existe una esencia de Europa, una lista fijada de valores europeos. No existe ninguna finalidad en el proceso de integración europea." (...) "La pregunta sobre el contenido de los valores europeos no es una pregunta filosófica que pueda responderse a priori; ni es una mera pregunta histórica. Es una pregunta que pide decisiones políticas frente a las tareas futuras a las que debe hacer frente la UE." Desde estos presupuestos, los sabios extraen diversas conclusiones, por ejemplo, "Si Europa no es un hecho, sino una tarea, tampoco puede haber unos límites europeos fijados para siempre, ya sean internos o externos. También las fronteras de Europa tienen que renegociarse siempre", o también conclusiones respectos a los así llamados valores europeos: "no cabe justificación alguna para intentar imponer a otros pueblos, con ayuda quizá de las instituciones de una política exterior y de defensa común, cualquier catálogo específico de valores"2.

Estas reflexiones de los sabios franceses, así como las anteriores de Vargas Llosa (2004), son sólo un ejemplo del auténtico trasfondo de la

\footnotetext{
${ }^{1}$ Poco más adelante añade: "Y, por otro lado, si bien las ideologías políticas propiamente dichas están en una crisis terminal, el esquizofrénico modo de pensamiento imperante, militantemente constructivista y antitradicional, con lo que es al mismo tiempo deconstuctivista, un eco del contractualismo político, es todavía muy fuerte: du passé faisons table rase!, se canta en la Internacional; Plus de Pères! Decía en 1852 con el mismo espíritu nada menos que el historiador Michelet; 'Il faut reconmmencer à zero', proclamó Le Corbisier en los albores del S. XX" (p. 116). D. Negro distingue entre las "ideologías" en su sentido estricto y el "pensamiento ideológico", los derivados posmodernos de aquéllas. ${ }^{2}$ Los denominados "sabios" en cuestión eran: Kurt Biedenkopf, antiguo primer ministro de Sajonia (Alemania); Bronislaw Geremek, antiguo ministro de asuntos exteriores de Polonia; Krzysztof Michalski, presidente del Instituto de Ciencias Humanas de Viena; y Michel Rocard, antiguo primer ministro de Francia. Una traducción de estas reflexiones apareció en el diario español: La Vanguardia, 5 de diciembre de 2004.
} 
cuestión. A su vez indican las radicales diferencias políticas e históricas que están juego a partir de la comprensión teórica de la identidad Europa y de sus valores. Es un claro intento de volver a raptar Europa.

\section{El proceso de deconstrucción y reconstrucción aplicado a la "nueva Europa"}

J.G.A. Pocock (2002), autor clave en el neorepublicanismo maquiaveliano y nada sospechoso de tradicionalismo, señala en un estudio sobre la identidad europea a través de su Historia lo siguiente: "De hecho, percibo que una construcción llamada 'Europa' está siendo inventada e impuesta sobre mí en unos términos que sugieren que debo aceptarlo sin preguntar demasiadas cosas sobre lo que exactamente sea, y soy muy escéptico sobre los motivos por los cuales esto se está haciendo" (p. 55). Algo más adelante Pocock afirma que Europa no es sólo una construcción o un invento, también es una realidad. La respuesta de Pocock a esas preguntas seguramente no serán muy amables con la identidad cultural cristiana, pero la negación directa de la realidad europea para sustituirla por una tarea, un invento, un proceso, o una construcción, revelan la intención de manipular esa identidad europea. Pocock también ha analizado el proceso de deconstrucción de Europa en un artículo titulado precisamente: "Deconstructing Europe" (1991) ${ }^{3}$

Se ha aludido repetidamente a un proceso de deconstrucción y de reconstrucción ideológica de la nueva Europa. Pero, ¿cuáles son los rasgos de este espíritu ideológico que se quiere insuflar en el proceso de integración europea? Lo primero es indicar que no se trata de una ideología claramente definida. Es más bien un conglomerado de sub-ideologías, de interconexión diversa, aunque todas ellas herederas del espíritu de la Ilustración, del Romanticismo y del proceso histórico de la Revolución Francesa. Consiste, pues, en una síntesis de racionalismo y de liberalismo ilustrado del S. XVIII, de Romanticismo y de Socialismo decimonónico. En un sentido más reciente, se une a estas raíces modernas, un cúmulo de movimientos ideológicos derivados de aquellas, como el nacionalismo, el progresismo liberal o socialista-, y el laicismo.

De modo que sintetizando esta mixtura ideológica, estaría compuesta básicamente por elementos neoilustrados, neorrománticos y posmodernos. Desde esta matriz se proyectan distintas actitudes y concepciones de la identidad cultural europea según predomine alguno de esos elementos en el compuesto ${ }^{4}$.

Pero, al margen de sus diferencias internas y sus contradicciones, en el nivel más básico de esta matriz ideológica predomina una cierta aversión hacia la identidad cultural europea, al menos en aquellos que desde estos postulados no manipulan el concepto para que signifique "ideología europeísta". La causa principal de esta fobia, más o menos encubierta, radicaría en que la identidad cultural, en coherencia, plantea una cierta e inevitable necesidad de partir de la tradición europea y de su Historia. En este sentido de deconstrucción de una vieja Europa y de reconstrucción de una nueva, el concepto de identidad cultural, parece que deviene en obstáculo. La identidad implica una permanencia y la pervivencia de una tradición con unos rasgos comunes constantes. La identidad implica ser un sí mismo (origen latino), conlleva la permanencia en una realidad pre-existente ${ }^{5}$. De ahí, que la

\footnotetext{
${ }^{3}$ Reimpreso posteriormente en P. Gowman, and P. Anderson (eds.), The. Question of Europe. Verso, Londres, 1997. También desarrolla esta misma línea en otro artículo titulado "Vous autres Europénnes -or Inventing Europe" (1993).

${ }^{4}$ Es curioso observar como la ideología europeísta ha logrado conciliar corrientes de pensamiento que en su esencia y en su desarrollo histórico se oponían mutuamente, por ejemplo el Romanticismo frente a la Ilustración $\mathrm{y}$, posteriormente, la Postmodernidad como movimiento opuesto al racionalismo ilustrado y a la sublimación sentimental de los grandes relatos sobre las tradiciones y las identidades nacionales del pensamiento romántico. O también la conciliación de los opuestos en cuanto se refiere al Liberalismo y al Socialismo. Se reproduce en este caso el proceso histórico-dialéctico hegeliano de la tesis, antítesis y síntesis.

${ }^{5}$ Lo cual no tiene que conducir a ontologizar el hecho europeo, ni a un "nacionalismo europeo". Es cierto que ni Europa, ninguna otra identidad o patria pueden considerarse realidades metafísicas naturales y cerradas, pero la idea de "proceso" y de "tarea" que defienden las posturas aquí expuestas, implica que la identidad europea es reconstructivamente maleable.
} 
exhortación que Juan Pablo II hizo a Europa: "¡Sé tú misma!"6, sea equivalente a la necesidad de que Europa mantenga su propia identidad, que no niegue lo más auténtico de su propio ser. Pero si esta identidad se respeta, surgen con claridad sus raíces religiosas cristianas. Todo ello comprometería en alto grado la dirección neoilustrada y laicista que se pretende conferir al proceso de integración y redefinición de Europa.

\section{La idea (neo)ilustrada y (neo)romántica de Europa}

No obstante, si analizamos con más detalle la Ilustración francesa, de la que proceden las ideologías europeístas dominantes, es cierto que el elemento laicista, materialista e incluso anticristiano o anticatólico, ha sido en ocasiones exagerado o malinterpretado. Como señala F. Copleston (1991) al analizar la Ilustración Francesa en su Historia de la Filosofía: "Parece haber una tendencia natural en muchos a concebir la Ilustración Francesa primordialmente como una crítica destructiva y una abierta hostilidad contra el Cristianismo, o por lo menos contra la Iglesia Católica" (pp. 15-16), poco más adelante matiza:

Es verdad, por otra parte que todos los filósofos considerados como representantes típicos de la Ilustración Francesa se oponían, en diversos grados, al dominio de la Iglesia. Muchos de ellos se oponían también al cristianismo, y algunos fueron ateos dogmáticos, resueltamente opuestos a toda religión, producto para ellos de la ignorancia y el temor, enemiga del progreso intelectual y obstáculo a la moralidad verdadera... Desde luego se atacó en nombre de la razón a la Iglesia católica, la religión revelada y, en ciertos casos, toda forma de religión. Pero el ejercicio de la razón era para los filósofos de la Ilustración Francesa mucho más que la simple crítica destructiva practicada en la esfera religiosa. La crítica destructiva era, por así decirlo, el lado negativo de la Ilustración. El lado positivo consistía en el intento de entender el mundo y, especialmente, el hombre mismo en su vida psíquica, moral y social. (pp. 15-16).

En este fragmento, de propósito ecuánime, encontramos el elemento deconstruccionista y el de reconstrucción de la nueva Weltaunschauung ilustrada, que comprenderá una nueva visión de Dios, del mundo, del hombre y de la Historia.

Pero hay que reconocer en la Ilustración una cierta apreciación del cristianismo. El mismo Juan Pablo II ha señalado en repetidas ocasiones las raíces cristianas de muchos de los valores de la Ilustración y de la propia Revolución Francesa. Aunque, parafraseando a G.K. Chesterton [y, según el historiador J. M. Cuenca Toribio, a Pío VII], nos encontraríamos ante principios cristianos que se han vuelto locos. Pero no adelantemos la argumentación.

Los principales autores de la Ilustración reconocen el papel esencial del cristianismo en la Historia de Europa. En la Enciclopedia de la Ilustración, dirigida por Diderot y D’Alembert, la voz "Europa", escrita por Chevalier de Jaucort, tras unas precisiones filológicas, recoge lo siguiente: "Si Europa es la más pequeña de las cuatro partes del mundo por su extensión, es sin embargo, la más importante por su comercio, navegación, fertilidad, por la ilustración e industria de sus gentes, por el conocimiento de las Artes, las Ciencias... y lo que es más importante, por el cristianismo" ("Ecyclopédie", 1996, pp. 211212). Voltaire (1957) es uno de los primeros intelectuales en hablar directamente de una "Europa cristiana", cuando afirma:

Durante mucho tiempo se pudo considerar a la Europa cristiana, con excepción de

\footnotetext{
${ }^{6}$ Se trata de un discurso que dio en una de sus visitas a España, el 19 de noviembre de 1982 en la Catedral de Santiago de Compostela, donde dijo más concretamente: "¡Europa, vuelve a encontrarte. Sé tú misma, Aviva tus raices!".
} 
Rusia, como una especie de gran república, dividida en varios Estados, unos monárquicos, otros mixtos, éstos aristocráticos, aquellos populares, pero todos relacionados entre sí: todos con un mismo fondo religioso aunque dividido en sectas: todos con los mismos principios de derecho público y de política, desconocidos en el resto del mundo (p. 620).

Asimismo, en El espíritu de las leyes (2002, libro XXIV, cap. 3), Montesquieu afirma que la unificación de las gentes europeas bajo la influencia espiritual del cristianismo los predispuso a la moderación, la humanidad y supuso una lucha contra las prácticas despóticas. Jean Jacques Rousseau (1964) afirma que "Europa, incluso ahora, está más en deuda con el cristianismo que con cualquier otra influencia para la unión... que pervive entre sus miembros" (p. 566). Por no hablar del socialista utópico y positivista ilustrado Saint-Simon y de su obra de 1825 titulada Nuevo Cristianismo ${ }^{7}$ o de sus Memorias sobre la ciencia del hombre (1813), donde subraya el papel pionero de Carlomagno en la Historia de Europa al ser el primero que organizó verdaderamente la sociedad europea.

Todo ello parece refutar una confrontación entre Ilustración y cristianismo, e incluso parece apuntar hacia todo lo contrario. G. Spadolini (1997) en una obra titulada "La idea de Europa entre la Ilustración y el Romanticismo" viene a subrayar esta perfecta compatibilidad entre Ilustración y cristianismo: "Tal y como se ha configurado en el mundo moderno, la idea de Europa nace del encuentro entre Cristianismo e Ilustración, entre la fe en la redención cristiana y la creencia en la laica dignidad del hombre, entre el ideal evangélico y el ideal democrático, entre la civitas dei y la civitas hominis" (p. 7). Aunque, poco después, este mismo autor se hace una pregunta interesante: "¿Cómo sobrevive en el siglo XVIII esa idea europea, cristiana e ilustrada al mismo tiempo, de la que somos hijos y beneficiarios? [y añade] Este es el gran problema que ha atormentado a los historiadores, el problema que domina las páginas de la Storia
d’Europa de Croce; la cuestión a la que responde la indagación, penetrante y profunda, de Federico Chabod Storia dell'idea d'Europa" (p. 10).

Sin embargo, junto a esta interpretación de una relación intelectual relativamente idílica entre Ilustración y cristianismo, existen otras interpretaciones que han señalado precisamente cómo en el origen mismo de la Ilustración late una oposición frente al cristianismo, en tanto que símbolo prístino del Antiguo Régimen y de la Época Antigua que había que derrocar. J.G.A. Pocock (2002) coincide con G. Spadolini en que la idea de Europa y de su historia se hace autoconsciente en la era de la Ilustración con Voltaire, Gibbon, Hume, Robertson, Raynal y Diderot. Pero no coincide en la relación positiva entre ambos, pues como prosigue indicando lo siguiente: "Escribir la historia para ellos fue un arma contra la Iglesia, tanto Protestante como Católica, y en consecuencia escribieron una historia de la Iglesia diseñada para reducirla a Historia secular" (p. 62). Continúa Pocock señalando algo harto conocido, a saber que las Historias que escribieron los ilustrados tuvieron como objetivo mostrar que la Iglesia había destruido la cultura antigua griega y romana. Para Gibbon el final de la época antigua comienza con Carlomagno y con la imposición del poder feudal y clerical. La época medieval misma será considerada una época intermedia, un paréntesis oscuro entre la época antigua y la moderna. La misma época moderna se entenderá por oposición a la medieval. A partir de esa revisión de la Historia de Europa sobre el medioevo cristiano, la Ilustración construye su Filosofía de la Historia. La clave de ésta radicará, en su faceta negativa, en la crítica histórica del Antiguo Régimen sintetizado en el Trono y el Altar, y en su faceta propositiva en la idea de un progreso automático y necesario en cuanto a la ciencia y la técnica se refiere. Pero dicho progreso requerirá igualmente, en adelante, la ilustración ideológica de la sociedad y el avance del proceso laicista

\footnotetext{
${ }_{7}^{7}$ El conde de Saint-Simon también escribió una obra sobre la sociedad europea titulada: Sobre la reorganización de la sociedad europea (1814), en colaboración con el historiador A. Thierry.
} 
de secularización. Se trata de la reconstrucción de un nuevo ciudadano europeo de acuerdo con la frase de Condorcet: "los ciudadanos no nacen; son creados a través de la instrucción" (citado en Withol 1997) ${ }^{8}$. Esta difusión de las ideas ilustradas por todas las ciencias y por la entera sociedad supondrá, por tanto, la expansión de una actitud crítica hacia la religión tanto por su esencia irracional como por las funestas consecuencias de su existencia histórica, según la concepción ilustrada.

Las aproximaciones al mismo no aspiran a una elevación de las ideas ilustradas a una categoría religiosa, sino más bien a ideologizar la religión cristiana de acuerdo con los principios ilustrados. Se tratará de reducir el cristianismo a una dimensión moral y horizontal de valores filantrópicos, para así transformar la fe cristiana en una religión de la humanidad o religión civil, como propusieron muchos ilustrados deístas. Éste es el propósito ilustrado que SaintSimon desarrolla explícitamente en su obra Nuevo cristianismo (1825).

En realidad, tanto la ideología ilustrada como el Romanticismo ejercerán progresivamente el papel "religión sustitutoria" del cristianismo. Como señala G. Steiner en Nostalgia del Absoluto (2001) refiriéndose a las grandes ideologías occidentales: "Esos grandes movimientos, esos grandes gestos de la imaginación que en Occidente han tratado de sustituir a la religión, y al cristianismo en particular, son muy semejantes a las iglesias, muy semejantes a la teología que pretenden reemplazar. Quizá podríamos decir que en toda gran batalla uno empieza a hacerse semejante a su enemigo" (p. 20).

Es ciertamente difícil no reconocer estos rasgos de la Ilustración en la nueva ideología europeísta. Pero la situación es peor aún, puesto que lo que influye en este proceso no es la Ilustración en una versión directa, se trata más bien de una neo-Ilustración, es decir, de la interpretación contemporánea que ha radicalizado el carácter laicista de la Ilustración. A ello habría que unir el contagio de elementos del Romanticismo y de la Postmodernidad.

Pasemos ahora a analizar algunos de los rasgos del Romanticismo que influyen en la formación del proceso de reconstrucción del êthos europeo. Dalmacio Negro (2004) ha subrayado la importante influencia del Romanticismo en todo este proceso, priorizándola incluso sobre la Ilustración.

El caso del Romanticismo es, en efecto, más complejo aún si cabe respecto del cristianismo. Nuevamente, como ocurría con la Ilustración se pueden hablar de un romanticismo que afirma el cristianismo. Muchos románticos, en su ataque a la razón ilustrada, miran positivamente hacia la fe y hacia la religión cristianas. E incluso se produce una recuperación idealizada de la época medieval. Lo medieval se convierte en un lugar y un tiempo de constante recreación romántica. En el ámbito ensayístico Novalis escribe Cristiandad o Europa en 1799 donde apela a la Res publica cristiana, en una añoranza de los "hermosos y espléndidos tiempos... en los que Europa era una tierra cristiana, donde una sola cristiandad habitaba una parte del mundo humanamente configurada y un único y un único y gran interés común unía a las provincias más remotas de este vasto reino espiritual".

Entonces, ¿dónde está la contradicción con el cristianismo? Sin duda hay elementos cristianos en el Romanticismo, como la afirmación del individuo, la recuperación de lo religioso y lo cristiano. Pero también hay que tener en cuenta el reverso mismo de estos elementos, que supone: una mística teosófica, una exaltación prometeica del yo, la disolución panteísta de Dios en la naturaleza o en el devenir histórico. También hay que observar la sobrevaloración de lo sentimental y lo pasional como norma de conducta frente a las normas morales establecidas, llegando a la fascinación por el suicidio como supremo acto

${ }^{8}$ La misma autora añade: "El Homo Europeannus aún está esperando ser 
de rebeldía autoafirmadora ${ }^{9}$. Y, por supuesto, la exacerbación de las identidades nacionales que degenera en el nacionalismo.

Pero en su proceso de despliegue, el Romanticismo, señala Dalmacio Negro (2004): "Empezó a convertir creencias en ideas y a mitificar ideas, provenientes muchas de ellas de la centuria anterior. De ahí su ambivalencia ante la religión, tanto en su defensa como en su oposición al cristianismo" (p. 39). Como resultado, la identidad romántica será otra identidad ideologizada e ideologizadora de las diversas dimensiones humanas: la religión, la historia, el arte. El cristianismo vuelve a ser un símbolo reinterpretable, esta vez como seña estética de identidad, adaptada al espíritu romántico.

Junto al nacionalismo, también el marxismo puede considerarse en buena parte heredero de la actitud romántica. Ciertamente, Marx, es un hijo de la Ilustración en muchísimos aspectos que saltan a la vista. Pero, aunque menos evidente, también cabe subrayar la faceta romántica del proyecto marxista. En la misma obra de G. Steiner (2001) citada anteriormente, asevera: "El escenario mitológico del marxismo, no es sólo expresamente dramático, sino que es también representativo de la gran corriente europea de pensamiento y sentimiento que llamamos Romanticismo. Como otras construcciones propias de la utopía social, de la salvación mesiánica y secular que siguieron a la revolución francesa, el marxismo puede ser expresado en los términos de una épica histórica" (p. 23). Pero apunta algo aún más interesante: la comparación que hace Marx de sí mismo con la de Prometeo. El joven Marx se interesó mucho por el mito de Prometeo dedicando algunos poemas y múltiples referencias a lo largo de su obra a esta figura emblemática de la hybris que se rebela contra Dios por adquirir el fuego. Símbolo del fuego destructor y purificador con el que un nuevo Prometeo destruirá el viejo orden, mientras sus llamas iluminarán una nueva aurora de libertad. Según afirma Marx en su obra de juventud: Diferencia entre la filosofía de la naturaleza de Demócrito y Epicuro -de hecho es su tesis doctoral-, a la Filosofía le ha llegado el momento de apropiarse del mito de Prometeo y de oponer un odio prometeico: "a todos los dioses del cielo o de la tierra que no reconocen la conciencia humana como la divinidad suprema", a lo cual añade: "en el calendario filosófico Prometeo ocupa el primer rango entre los santos y los mártires" (Marx, 1980, p. 19). No en vano se denominó a Marx el "Prometeo de Tréveris".

Recapitulando lo afirmado sobre el Romanticismo se puede decir que estamos ante una Ilustración invertida (razón, sentimiento; progreso utópico-pasado mitológico; ciencia, arte y religión; etc.); por lo que la relación esencial que establecen ambas con el cristianismo convergen hacia una misma actitud instrumentalizadora. La diferencia estribaría en que mientras la Ilustración convierte al cristianismo en una ideología social moralizante, el Romanticismo lo convierte en un mitologema identitario.

\section{La reconstrucción posmoderna de la nueva "Europa"}

Un elemento del Romanticismo que hereda la Postmodernidad del Romanticismo y del fracaso del proyecto ilustrado, es el nihilismo. El nihilismo es constitutivo de la postmodernidad. Del nihilismo procede a su vez el relativismo, el agnosticismo, el hedonismo y gran parte de los "ismos" que caracterizan a la actual cultura decadente. P. Poupard apunta: "Trágico destino del ateismo travestido de religión y convertido en un elemento de civilización. Sísifo nunca se aleja de Prometeo. Y una cultura que se ha vuelto culturalista se agota en un juego de espejos estériles, se disuelve en el consumo o se desvanece en la insignificancia".

Dentro del contexto posmoderno y desde la herencia neoilustrada y neorromántica es donde

\footnotetext{
${ }^{9}$ La obra de Goethe titulada Las deventuras del joven Werther llegó a ser un emblema pasional de la generación romántica, de hecho hubo un notable número de suicidios por emulación de la actitud "vital" del protagonista.
} 
podemos ubicar la actual "ideología europeísta", de la cual D. Negro (2004) ha afirmado que: "cumple la función, dada la vigencia del modelo de pensamiento ideológico, de rellenar formalmente el hueco de las fenecidas ideologías totales" (p. 99).

Pero centrándonos en el concepto de identidad cultural, cabe apreciar en la postmodernidad una profunda aversión hacia concepto mismo de identidad. Esto es producto del odio moderno y posmoderno a la metafísica. En efecto, así como la Ilustración positivista atacó el concepto y el principio de causalidad (véase el famoso ejemplo de las bolas de billar de Hume), la filosofía posmoderna está interesada apriorísticamente en realizar un ataque al concepto de identidad. Se trata, igualmente, de la antigua oposición entre Heráclito y Parménides (del ser frente al devenir), de la Física moderna contra la Física y la Metafísica clásicas. Por ello, se tiende a considerar el principio de la identidad como el nuevo enemigo a batir. Wittgenstein habla, en este sentido, del infierno de la identidad.

Al concepto filosófico clásico de identidad, la postmodernidad le opone el concepto de diferencia. Hasta el punto de que se puede hablar de la filosofía posmoderna como una filosofía de la diferencia. El principal referente de ella sería Jacques Derrida. Para este autor, el ser es diferencia, por lo tanto, es irreductible a identidad. Desde este punto de partida propone la superación de la metafísica a través de su "deconstrucción".

Esta dicotomía entre la identidad y la diferencia se ha llevado al plano político sociopolítico. Una filósofa política nada sospechosa de clasicismo, Victoria Camps (citada en Gines y Scartezzini, 1996), afirma: "La diferencia está en auge. Es un signo de calidad. Significa distinción, poder y atributos para distanciarse de lo masivo. Es la expresión de la aristocracia en nuestro tiempo... se ha ido creando una ideología de lo individual y la diferencia como resultado de la exacerbación de la crítica de la modernidad y la ilustración..." (p. 137).

Pero esta ideología de la diferencia también se ha llevado al tema de la cultura europea. El actual debate posmoderno sobre la identidad cultural de Europa está marcado profundamente por el concepto de diferencia. En un lenguaje característico Leszek Kolakowski sostiene que "la identidad cultural de Europa reside en la ausencia de cualquier identidad plenamente formada; en otras palabras, en la incertidumbre y el descontento", según reproduce y suscribe Vargas Llosa en su artículo antes referido. Gadamer en su ensayo de 1985 titulado $L a$ diversidad de Europa subraya que el principal objetivo político actualmente reside "en la experiencia del otro y de los otros" (Gadamer, 1990, pp. 152-153). A su vez señala que los trágicos eventos del s. XX han desmentido la existencia de una "unidad espiritual" europea (pp. 152-153). Tomar dicha unidad como una realidad iría en contra de la sensibilidad moderna, es necesario tomarla pues como un deber (Passerini, 2002, p. 190). La aplicación del deconstruccionismo derridiano a la idea de Europa la encontramos, por ejemplo, en su obra El otro cabo (Derrida, 1992).

Por eso, los pensadores y políticos que utilizan el armamento intelectual de la ideología de la diferencia para aplicarlo a la negación de la identidad cultural de la UE, utilizan toda una pléyade de términos peyorativos que asocian a dicha identidad, tales como amenaza esencialista, antipluralismo, monismo, exclusión, estatismo o inmovilismo, etc. Desde la ideología de la diferencia, por tanto, se presenta la identidad cultural europea de un modo deformado y caricaturizado, al sugerir que la afirmación de una identidad cultural europea, sería, en su quintaesencia, contraria al pluralismo, la democracia, la tolerancia, el multiculturalismo, etc.

En fin, concluyendo, quisiera añadir que nos encontramos ante una importante batalla intelectual en la que necesitamos el modelo 
religioso y cultural de un San Benito. A. MacIntyre (2001) acaba su magistral libro Tras la virtud con las siguientes palabras: "Y si la tradición de las virtudes fue capaz de sobrevivir a los horrores de las edades oscuras pasadas, no estamos enteramente faltos de esperanza. Sin embargo, en nuestra época los bárbaros no esperan al otro lado de las fronteras, sino que llevan gobernándonos hace algún tiempo. Y nuestra falta de conciencia ante ello constituye parte de nuestra difícil situación. No estamos esperando a Godoy sino a San Benito" (pág. 322). Querría añadir a estas palabras que si nuestra vieja Europa quiere seguir siendo hoy "fermento de civilización" y "levadura" para el mundo entero" ${ }^{10}$, necesita más que nunca de este nuevo San Benito, puesto el rapto de Europa no es una narración mitológica es una narración profética.

\section{Referencias}

Copleston, F. (1991), Historia de la Filosofía, Barcelona, Ariel.

De Lucas J. (1993), Europa: ¿convivir con la diferencia? Madrid, Tecnos.

Derrida, J. (1992) El otro cabo. Barcelona, Ediciones del Serbal.

Gadamer, H. G. (1990), La herencia de Europa, Barcelona, Península.

MacIntyre, A (2001). Tras la virtud. Barcelona, Crítica.

Marx, K. (1980), "Diferencia entre la Filosofía democriteana y epicúrea de la naturaleza". En: Marx, K. Escritos de Juventud. Fondo de Cultura Económica, México,

Montesquieu, C. L. (2002), El espíritu de las leyes, Madrid, Istmo.

Negro, D. (2004), Lo que Europa debe al cristianismo, Madrid, Unión Editorial.

Novalis, F. (1977), Cristiandad o Europa, Madrid, Instituto de Estudios Políticos.
Padgen, A. (edit.), (2002) The Idea of Europe, Cambridge, Cambridge University Press.

Poupard, P. (2007), La herencia cristiana de la cultura europea, trad. de Cano Méndez, S. Disponible en Internet: http://www.arvo. net $/$ d ocumento.asp?doc $=042221 \mathrm{~d}$ (consultado en 2007).

Passerini, L. (2002), "From the ironies to Identity", en Padgen, A. (edit.) The Idea of Europe, Cambridge, Cambridge University Press.

Pocock, J.G.A, (2002), "Some Europes in Their History", en Padgen, A. (edit.) The Idea of Europe, Cambridge, Cambridge University Press.

_- (1993), "Vous autres Europénnes -or Inventing Europe", en Acta Philosophica 14, núm 2, pp. 141-58.

_ (1991), "Deconstructing Europe", en History of European Ideas, núm. 3, pp. 329-46.

Vargas Llosa, M. (2004, 12 de diciembre), "Europa, ¿una bella idea?", en El País.

Sánchez Meca, D. (2003), "El sueño de una Europa de los pueblos: el dilema entre identidad y diversidad", en En torno a Europa, Madrid, FAES, pp. 65-120.

Spadolini, G. (1991), La idea de Europa entre la Ilustración y el Romanticismo, Madrid, Edersa.

Steiner, G. (2001), Nostalgia del Absoluto, Madrid, Siruela.

\footnotetext{
${ }^{11}$ Son expresiones que emplea Benedicto XVI en su: Discurso del Santo Padre Benedicto XVI a un congreso organizado con ocasión del 50 aniversario de la firma de los Tratados de Roma, 24 de marzo de 2007. Disponible en internet:

http://www.vatican.va/holy_father/benedict_xvi/speeches/2007/march/ documents/hf_ben-xvi_spe_20070324_comece_sp.html
} 
Voltaire F. (1957), Oevres historiques, t. I. Le siècle de Louis XIV, Paris, éd. PomeauGallimard.

Withol de Wenden, C. (1997), La Citoyenneté europénne, París, Ed. Presses de Sciences of Po

Ecyclopédie (1966), vol. 6, F. Frommann, Stuttgart-Bad Cannstatt. 
